ORIGINAL ARTICLE

\title{
Diversity of trends in occupational injury mortality in the United States, 1980-96
}

\author{
D Loomis, J F Bena, A J Bailer
}

Injury Prevention 2003;9:9-14

\begin{abstract}
Objectives: Although the United States has generally enjoyed declining rates of fatal occupational injury, the rate of decline has not been uniform. To examine the heterogeneity of trends, changes in fatal occupational injury rates from 1980 to 1996 were estimated by occupation, industry, geographic region, and demographic group.

Methods: Deaths due to injury at work during 1980-96 were identified from the US National Traumatic Occupational Fatality database and populations at risk were estimated from the census of population. Mortality rates were computed for unintentional injuries, homicides, and all injuries combined. The annual rate of change was estimated using Poisson regression to model the death rate as a function of time.

Results: The estimated average rates for all fatal occupational injuries and for unintentional injuries declined by $3 \%$ per year, while the estimated rate of homicide declined $<1 \%$ per year. The improvement was faster for men (3\% per year) than for women $(<1 \%$ per year) and for younger relative to older workers (7\% per year v $2 \%-3 \%$ per year). Trends were also geographically heterogeneous, with the most rapid declines (7\%-8\% per year) in the South and West. Injury rates for most occupations and industries declined at near the average rate, but some experienced no change or an increase. The rate of homicide also increased in a number of occupations and industries.

Conclusions: Broad downward trends in occupational fatality rates may be explained by several factors, including organized safety efforts, product and process changes, and the ongoing shift of employment toward safer sectors. Disparities in fatal injury trends draw attention to potential opportunities to reduce risk: work settings with increasing injury rates are of particular concern.
\end{abstract}

See end of article for authors' affiliations

Correspondence and reprint requests to:

Professor Dana Loomis,

Department of

Epidemiology, CB-7435

UNC-CH, Chapel Hill NC

27599-7435, USA

Dana.Loomis@unc.edu
O n a national level, the United States has enjoyed declining rates of fatal occupational injury for at least two decades. Despite growth in the size of the labor force, the number of workers dying on the job decreased from approximately 7300 in 1980 to 5300 in 1995, with an accompanying reduction in the annual rate of fatal occupational injuries from 7.4 to 4.3 per 100000 workers. ${ }^{1}$ Virtually every segment of the workforce and major industrial sector experienced a downward trend in fatal injury rates during the 1980s and early 1990s. ${ }^{1-3}$

While these trends are encouraging, the rate of improvement in fatal injury rates has not been uniform. Some research suggests that for some groups of workers the rate of decline in the fatality rate was notably slower than the average decrease of about $3 \%$ per year. ${ }^{23}$ Workers over age 60 experienced a decline of less than $1 \%$ per year, for example, as did the important retail industry sector. ${ }^{2}$ Analyses of state level data indicate that some industries actually experienced substantial increases in fatal injury rates during the 1980s. ${ }^{4}$ These findings suggest that examination of fatal injury trends on a broad, national level may mask important variation in the rate of change.

To update previous descriptions of trends in fatal occupational injury and examine the range of trends among demographic groups, occupations, industries, geographic regions, and major categories of injury, we used Poisson regression to model trends in fatal occupational injury rates in the United States during the years 1980-96.

\section{METHODS}

Occupational injury deaths were identified via the National Traumatic Occupational Fatalities (NTOF) surveillance system, a data base compiled by the US National Institute for
Occupational Safety and Health using death certificates from the 50 states, New York City, and the District of Columbia. The NTOF system includes all deaths of persons age 16 or older that are certified as the result of injuries (International Classification of Diseases, 9th revision codes E800-E999) that the death certificate indicated were sustained "on the job". ${ }^{5}$ Deaths in the workplace from suicide, medical misadventure, non-work related choking on food or other objects, non-occupational poisoning by therapeutic drugs or beverage alcohol were excluded.

The remaining, eligible deaths in the NTOF system were tabulated simultaneously by calendar year, sex, age, race, occupation, industry, and geographic area. Age was aggregated in categories of $16-19,20-49,50-64$, and $\geqslant 65$ years. The ability to identify races and ethnic groups was limited by the information provided on the death certificate, so race categories of white, black, and other were the only ones employed. No consistent indicator of Hispanic or Latino ethnicity was available throughout the study period, and workers of other classified race groups were not sufficiently numerous for separate analysis. For occupation and industry, we collapsed the three digit United States census codes from the death certificate as in a previous study to form 30 occupational and 48 industrial categories. ${ }^{6}$ Geographic areas were based on the United States regions and divisions defined by the Bureau of the Census. ${ }^{7}$

For each cell defined by the preceding variables, we estimated the workforce at risk from the 1980 and 1990 census of population (the necessary data from the 2000 census are not yet available). Workforce sizes in intercensal years were estimated by linear interpolation and extrapolation.

Merging the death data with the workforce estimates required exclusion of observations with invalid or missing 
Table 1 Estimated fatal occupational injury rate per 100000 worker years in 1980 and estimated annual rate of change 1980-96 by demographic group and cause of death

\begin{tabular}{|c|c|c|c|c|c|c|c|c|c|}
\hline & \multicolumn{3}{|l|}{ All injuries } & \multicolumn{3}{|c|}{ Unintentional injuries } & \multicolumn{3}{|l|}{ Homicide } \\
\hline & 1980 rate* & $\begin{array}{l}\text { Annual \% } \\
\text { change* }\end{array}$ & $95 \% \mathrm{Cl} \dagger$ & 1980 rate & $\begin{array}{l}\text { Annual \% } \\
\text { change }\end{array}$ & $95 \% \mathrm{Cl}$ & 1980 rate & $\begin{array}{l}\text { Annual \% } \\
\text { change }\end{array}$ & $95 \% \mathrm{Cl}$ \\
\hline All workers & 5.78 & -3.28 & -3.42 to -3.15 & 5.08 & -3.70 & -3.85 to -3.55 & 0.71 & -0.90 & -1.24 to -0.55 \\
\hline \multicolumn{10}{|l|}{ Age } \\
\hline $16-20$ & 3.38 & -7.09 & -7.92 to -6.24 & 3.15 & -7.91 & -8.79 to -7.02 & 0.27 & -1.27 & -3.68 to 1.20 \\
\hline $20-49$ & 5.63 & -3.79 & -3.94 to -3.64 & 4.98 & -4.32 & -4.49 to -4.15 & 0.67 & -0.76 & -1.18 to -0.33 \\
\hline $50-64$ & 6.31 & -1.81 & -2.10 to -1.52 & 5.50 & -2.04 & -2.35 to -1.73 & 0.82 & -0.48 & -1.26 to 0.30 \\
\hline$\geqslant 65$ & 11.59 & -1.77 & -2.27 to -1.27 & 9.61 & -1.39 & -1.93 to -0.85 & 2.00 & -4.04 & -5.34 to -2.71 \\
\hline \multicolumn{10}{|l|}{ Sex } \\
\hline Men & 9.58 & -2.98 & -3.12 to -2.85 & 8.60 & -3.36 & -3.51 to -3.21 & 1.00 & -0.43 & -0.82 to -0.04 \\
\hline Women & 0.62 & -0.90 & -1.46 to -0.33 & 0.32 & -0.44 & -1.22 to 0.34 & 0.32 & -1.37 & -2.17 to -0.58 \\
\hline \multicolumn{10}{|l|}{ Race } \\
\hline Black & 6.09 & -3.17 & -3.57 to -2.77 & 4.82 & -3.82 & -4.30 to -3.35 & 1.28 & -1.15 & -1.98 to -0.32 \\
\hline White & 5.72 & -3.77 & -3.92 to -3.62 & 5.10 & -3.94 & -4.09 to -3.79 & 0.62 & -2.43 & -2.87 to -1.99 \\
\hline Other & 6.94 & -0.71 & -1.15 to -0.26 & 5.59 & -1.88 & -2.40 to -1.36 & 1.41 & 2.55 & 1.65 to 3.46 \\
\hline
\end{tabular}

*Estimated from the Poisson regression model $\log ($ rate $)=\beta_{0}+\beta_{1}($ year $) ; 1980$ rate $=100000\left[\exp \left(\beta_{0}\right)\right]$; annual percent change $=100\left[\exp \left(\beta_{1}\right)-1\right]$.

$+95 \%$ confidence interval $(\mathrm{Cl})$ for annual \% change.

data for sex, age, race, occupation, industry, and place of residence. Deaths in categories for which the estimated workforce was zero or smaller than the number of deaths were also excluded on the assumption that the recording of a death in such categories was the result of miscoding.

Rates of fatal occupational injury were estimated for each year as the count of injury deaths divided by the estimated number of workers employed in that year, which approximates worker years at risk. To estimate trends, we modelled the rate of fatal occupational injury as a function of calendar year using Poisson regression. ${ }^{8} 9$ The basic model had the form: $\log ($ rate $)=\beta_{0}+\beta_{1}($ year -1980$)$. Calendar year was entered as a continuous variable, scaled by subtracting 1980 so that the intercept $\beta_{0}$ has a natural interpretation as the log of the baseline fatality rate in the first year of the study. Estimated trends in the rate of fatal injury are reported here as the annual percent change, obtained from the fit of the Poisson regression model as $100\left[\exp \left(\beta_{1}\right)-1\right]$. As an aside, changes over longer periods of time can be similarly estimated. For example, the percentage change in fatal occupational injury rates over a 10 year period can be estimated as $100\left[\exp \left(10 \beta_{1}\right)-1\right]$.

Separate models were fit to estimate trends for all occupational injuries combined, unintentional trauma, and homicide, and the data were stratified to examine the effects of age, sex, race, and other factors in separate models.

\section{RESULTS}

The study included 85590 eligible deaths ( $90 \%$ of deaths from non-excluded causes) from injuries suffered on the job. Of this total, 72842 deaths were unintentional and 12748 were due to homicide. Estimates obtained from the Poisson regression models indicate that the rate of fatal injury decreased for all occupational injuries combined, for unintentional injuries and for homicide during this period (fig 1). For all injuries, the fatality rate declined at an estimated $3.3 \%$ per year from a baseline of 5.78 per 100000 worker years in 1980 (table 1), but the estimated rate of decline was steeper for unintentional injury (3.70\% per year) than for homicide ( 0.90 per year).

Workers in all age, sex, and race categories enjoyed reductions in the overall risk of injury during the study period, but the rate of change varied considerably among the groups (table 1). The overall fatal injury rate decreased most rapidly among workers younger than 20 years (over 7\% per year), while workers over age 50 experienced slower declines, on the order of $2 \%$ per year. The rate of improvement was faster for men than for women, although the absolute risk remained much higher for men. The trends for black and white workers were similar, but those for workers of other races were notably slower (table 1).

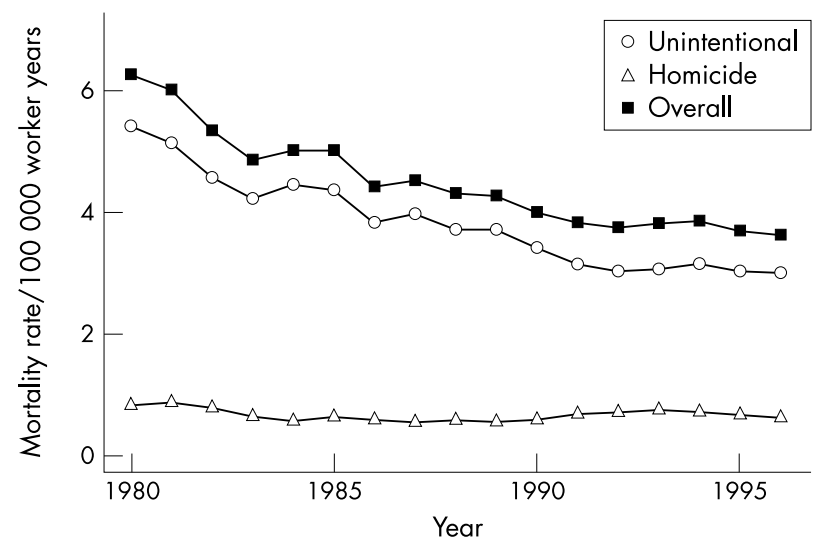

Figure 1 Annual mortality rates for unintentional occupational injuries, homicide at work, and all occupational injuries, United States, 1980-96.

Declines were generally slower for homicide than for unintentional injury. Women and workers over age 65 had more rapidly decreasing homicide rates, while the rate of homicide increased for workers of race categories other than black or white (table 1).

Most individual occupation and industry categories also saw fatalities decline at near the average rate of 3\% per year for all injuries. More rapid declines, on the order of $5 \%$ per year, were seen in some occupations and industries, including the military, technicians, precision production occupations, and in the industry categories of service stations, electric and gas utilities, and sawmills (fig 2). Others, including occupations related to agriculture, fishing, hunting and trapping, services, and transportation, and diverse industries in the sectors of manufacturing, services, and retail had slower declines or no improvement (fig 2). A few groups, notably health service occupations and the taxi industry, experienced increasing fatality rates over the study period (fig 2). The pattern of changes for unintentional fatalities was generally similar (data not shown).

For homicide, a larger number of groups, including workers in health service, occupations, several transportation and material moving occupations, and technicians, as well as the industries of communications, taxi services, public administration, and detective and protective services, experienced increasing rates (fig 3 ). The precision of the trend estimates for homicide was generally poor, however. A number of other industries and occupations experienced faster than average declines in the rate of homicide, but confidence intervals were 
A

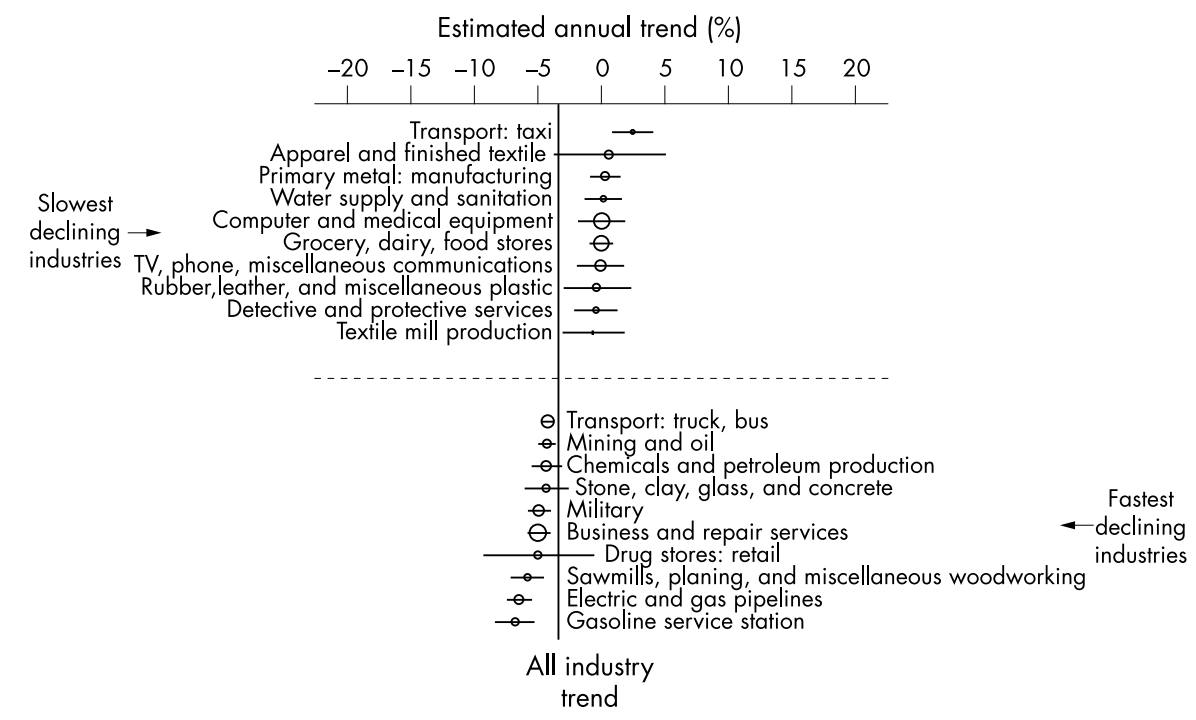

B

Estimated annual trend (\%)

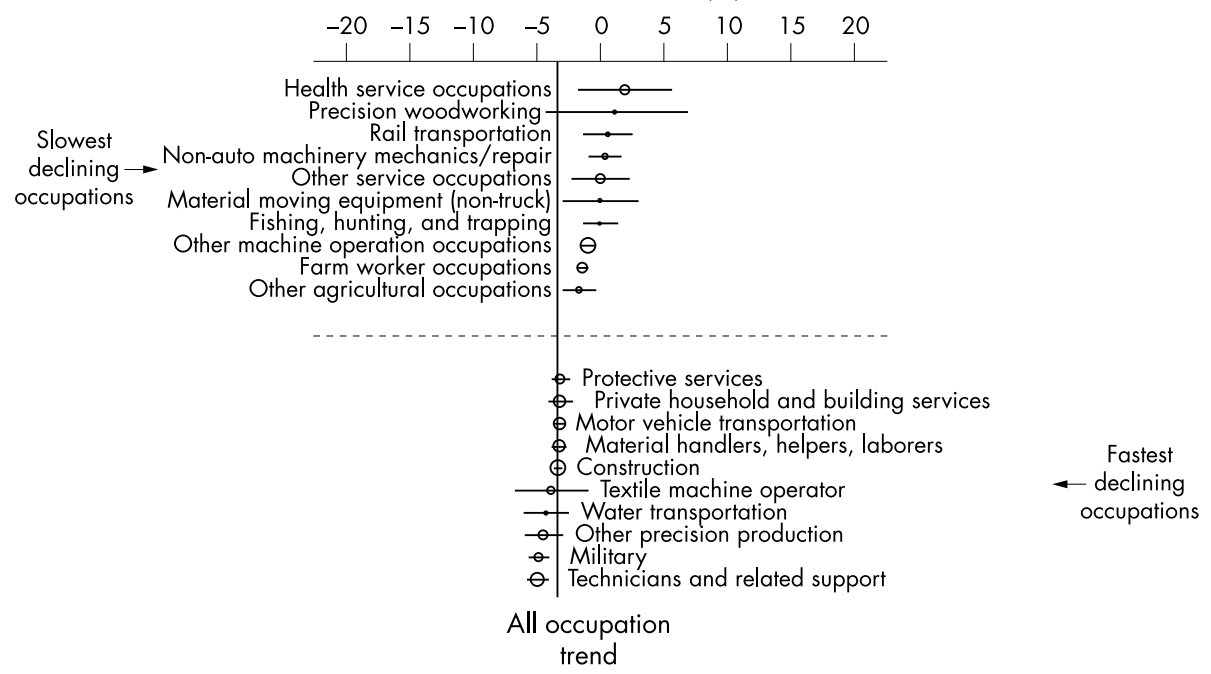

Figure 2 Plots showing estimated average annual change in the rate of all occupational injuries for the 10 industries (A) and 10 occupations (B) with the fastest and slowest rates of change. Circles indicating the point estimate are proportional to the number employed; error bars indicate the $95 \%$ confidence interval. Industries and occupations with less extreme rates of change are omitted.

again quite wide (fig 3). Protective service occupations and the gasoline station and entertainment and recreational services industries were notable for homicide rates that declined $2 \%$ to $7 \%$ per year and relatively narrow $95 \%$ confidence intervals.

All geographic regions of the United States experienced decreasing rates of occupational injury, but the rate of change was again quite variable (table 2 ). Southern and western states had the highest initial rates in 1980, but also had the steepest declines in the overall injury rate, ranging from $4 \%$ to $5 \%$ per year. At the other extreme, the Northeast had a low initial rate and a slower rate of decline $(0.6 \%$ per year) for all injuries. The pattern of changes in the rate of unintentional injury was generally similar, but changes in homicide rates were still more variable across regions (table 2 ). The West and Midwest experienced roughly equal rates of decline, at approximately $2.5 \%$ per year, while the decline was slower in the South, where the rate had been highest in 1980. In marked contrast, the rate of homicide in the Northeast increased nearly $7 \%$ per year.

\section{DISCUSSION}

Our findings are broadly consistent with the results of previous studies that reported downward trends in the rate of fatal occu- pational injury in the United States during the last two decades of the 20th century. We estimated that between 1980 and 1996 the overall rate of fatal workplace injury declined at a rate of $3.3 \%$ per year. Stout et al reported a $3.7 \%$ average annual rate of decline between 1980 and 1989, ${ }^{3}$ and Bailer et al reported a decline of $3.4 \%$ per year from 1983 to $1992 .^{2}$

These previous studies considered only the total injury rate, however. We found that the observed trends were driven primarily by declining rates of unintentional occupational injury, while the rate of homicide on the job declined much more slowly, at less than $1 \%$ per year. During the study period, homicide represented only about $15 \%$ of all workplace deaths in the United States, but was the second leading cause of death on the job for all workers (after motor vehicle incidents), and the leading cause for working women. ${ }^{1}$ Trends in the rate of workplace homicide tend to parallel those for homicide in general, which have declined gradually since the early 1980s, interrupted by a shallow peak in the early 1990s. ${ }^{10}$

Broad downward trends in unintentional occupational injury rates are subject to two general interpretations: this phenomenon could be explained by either improving safety across the spectrum of workplaces or by changes in the composition of the labor force, such that a decreasing proportion 
A

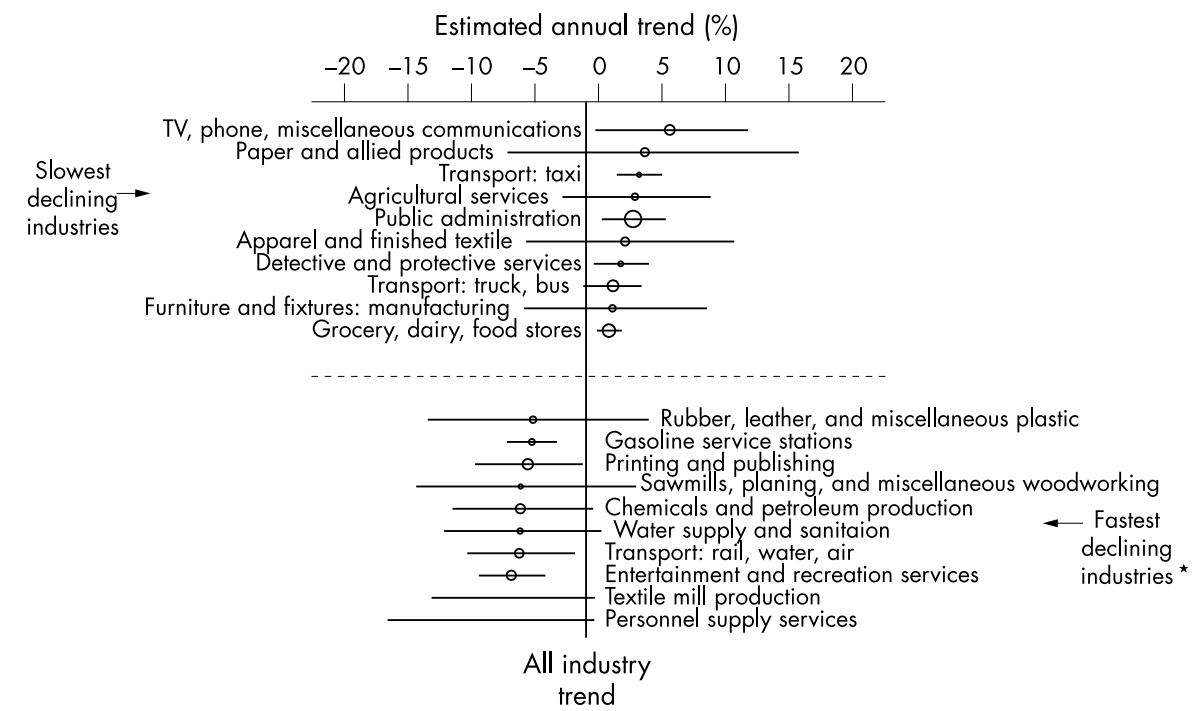

B

Estimated annual trend $(\%)$

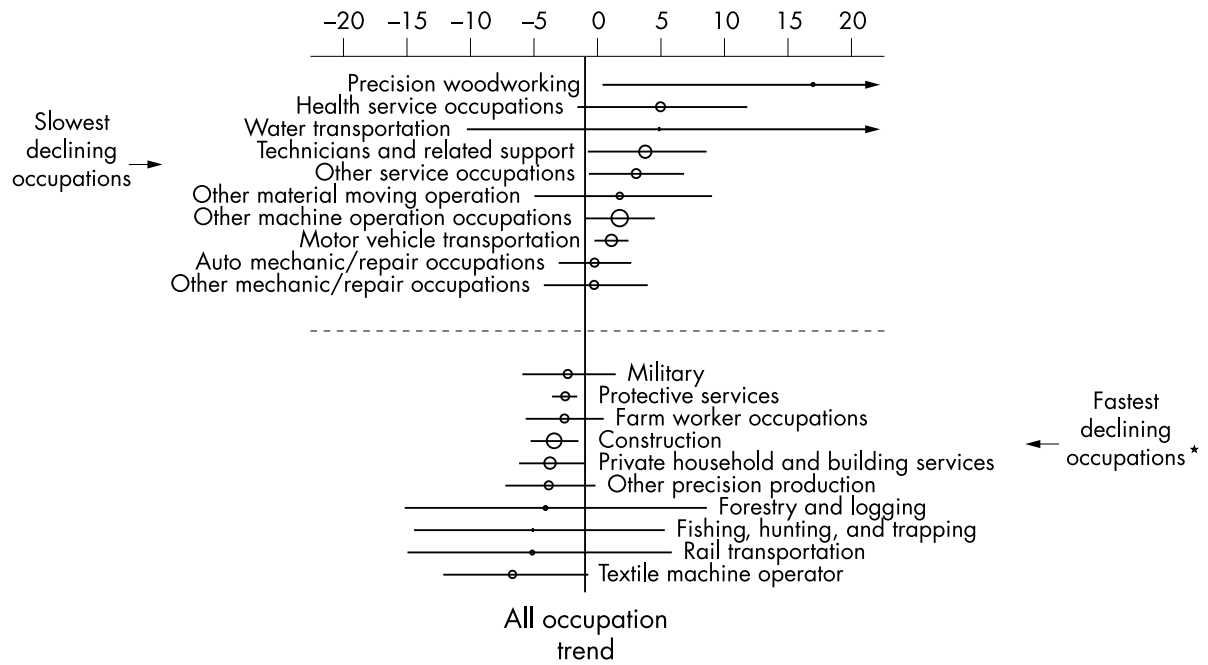

Figure 3 Plots showing estimated annual change in the rate of homicide at work for the industries (A) and occupations (B) with the fastest and slowest rates of change. Circles indicating the point estimate are proportional to the number employed; error bars indicate the $95 \%$ confidence interval. Occupations and industries with less extreme rates of change or with confidence intervals spanning the horizontal axis are omitted. *Fastest declining industries omit "wood buildings and mobile homes" (point estimated $=-0.26$ ) and "tobacco manufacturers" (point estimated $=-0.25$ ) because their confidence intervals span the entire range of the plot.

Table 2 Estimated fatal occupational injury rate per 100000 worker years in 1980 and estimated annual rate of change 1980-96 by geographic region and cause of death

\begin{tabular}{|c|c|c|c|c|c|c|c|c|c|}
\hline & \multicolumn{3}{|l|}{ All injuries } & \multicolumn{3}{|c|}{ Unintentional injuries } & \multicolumn{3}{|l|}{ Homicide } \\
\hline Midwest & 5.01 & -2.76 & -3.05 to -2.47 & 4.46 & -2.81 & -3.11 to -2.50 & 0.55 & -2.43 & -3.27 to -1.58 \\
\hline South & 7.81 & -3.76 & -3.96 to -3.55 & 6.76 & -4.14 & -4.37 to -3.92 & 1.07 & -1.73 & -2.23 to -1.23 \\
\hline West & 6.94 & -4.64 & -4.92 to -4.36 & 6.04 & -5.03 & -5.33 to -4.73 & 0.91 & -2.52 & -3.22 to -1.81 \\
\hline
\end{tabular}

${ }^{*}$ Estimated from the Poisson regression model $\log ($ rate $)=\beta_{0}+\beta_{1}($ year $) ; 1980$ rate $=100000\left[\exp \left(\beta_{0}\right)\right]$; annual percent change $=100\left[\exp \left(\beta_{1}\right)-1\right]$. †95\% confidence interval (CI) for annual \% change.

of workers are engaged in hazardous jobs. These hypotheses are not mutually exclusive, and our data provide some support for each of them.

Analyses of individual industries and occupations showed downward trends in injury rates that are consistent with widespread improvements in workplace safety. Safety may be improved as a direct result of deliberate interventions undertaken through regulation or voluntary efforts on the part of employers or workers, but improvements may also be an indirect byproduct of changes in products, processes, equipment, and materials. For example, automation or the adoption of closed systems may reduce risk by removing workers from the 
process of production. However, the observation that some industries and occupations experienced no change in injury rates or had increasing rates not only demonstrates that the benefits of improved safety were not shared uniformly, but suggests that increases in the proportion of workers employed in safer jobs may play a part in explaining the overall trend.

Beneath the global tendency toward decreasing risk of fatal injury on the job, we observed considerable diversity in the trends associated with geographic region and the worker attributes of race, sex, and age. These trends, too, can be considered in light of the same processes that influence fatal injury rates for the workforce as a whole. For example, the observation that women had a relatively low rate of unintentional fatal injury in 1980 and saw little improvement subsequently, while men had both higher rates at the beginning of the period and much more rapid rates of decline afterward, is consistent with the hypothesis that women began the period in relatively safe jobs and remained there, while the proportion of men working in lower risk jobs increased during the study period. Census data support this interpretation: the proportion of women employed in retail, services, banking, and other historically low risk sectors has remained relatively constant, while the number of men employed in these sectors has increased in concert with decreases in the number working in manufacturing, mining, farming, and other higher hazard industries.

The extent to which actual improvements in safety on the job might contribute to the differences in trends for women and men is difficult to assess, because data on exposure to hazards are not available. Nevertheless, the observation that fatality rates declined in such historically male dominated industries as mining, transportation, and the military suggests that improvements in working conditions may have played a part.

Geographic variation in occupational injury trends may be explained in part by the regional diversity of economic change. The South and West, which had both the highest fatality rates in 1980 and the most rapid declines in rates subsequently, have also experienced rapid economic changes that have tended to displace employment from such traditional industries as farming, mining, wood production, and fishing, toward jobs in the relatively safer service, retail, and technology sectors. ${ }^{41112}$ A shift of employment away from historically hazardous sectors, such as agriculture, may also have a role in explaining the greater improvements in safety enjoyed by younger workers, relative to older ones, and by white and black workers, relative to workers of other race groups. These hypotheses merit further investigation.

Indications of increasing injury risk for some work settings and segments of the labor force also require attention. These observations suggest that safety conditions may be deteriorating for some workers. Reduced investment in safety and increased production rates in highly competitive industries have been hypothesized as one possible cause of increasing rates of unintentional occupational injury. ${ }^{4}$ Increases in the risk of workplace homicide for some subgroups may be driven by general social trends in the occurrence of violence.

This study had several limitations. In the United States, death certificates are the most comprehensive source of information available on occupational injuries ${ }^{13}$ but they provide only limited information for each case. The description of the work environment is limited to titles for the decedent's "usual" occupation and industry, rather than those at the time of injury. Previous research suggests that death certificate occupational information is a reasonably good proxy measure of the last occupational activity, particularly when occupation and industry are categorized,,${ }^{14}{ }^{15}$ but some misclassification is to be expected. Other limitations of death certificate data have been discussed previously, and include underascertainment of work relatedness and difficulties in classifying ethnicity and race. ${ }^{131516}$ It should be noted that none of these problems

\section{Key points}

- For all US workers and all types of injuries combined, the rate of fatal injury on the job declined $3 \%$ per year from 1980 to 1996

- The rate of decline was not uniform, however: some worker groups and geographic regions enjoyed greater improvements than others.

- The rate of decline was also more rapid for unintentional injuries than for homicide.

- Unintentional injury and homicide rates increased for some occupations and industries.

- The reasons for disparities in the rate of decline in fatal occupational injury rates, or for increasing rates, are research questions to be explored in future studies.

affect the estimation of trends, as opposed to injury rates, unless their magnitude has changed systematically and substantially over time.

The census data used to characterize the population at risk have related limitations. The data identify respondents' current occupation and industry, but the lack of detail concerning exposures and working conditions for decedents as well as the population at risk is a weakness that precludes complete exploration of some questions.

Additional uncertainties are associated with the method of estimating the size of populations at risk of occupational injury. We used data from the 1980 and 1990 census of population and assumed linear growth between census years. The census sample is large and offers good precision, but population estimates for non-census years could be biased if the assumption of linear increase is incorrect. As an alternative, other researchers have used annual labor force data from current population surveys to estimate working populations. ${ }^{23}$ Sample sizes in the surveys are small, however, so the precision of the estimates is not as good as that of the census. The use of either data source therefore requires compromises between precision and validity. It should be noted, however, that estimates of trends in injury rates based on the census would be biased only if the true rate of change in workforce size diverged systematically from the assumed model. Methods for estimating the size of working populations require further evaluation. Nevertheless, the concordance between our census based trend estimates and the trends estimated by Bailer et $a l^{2}$ using the current population surveys suggest that these results are robust to the source of data used to estimate the population at risk.

Finally, we assumed that the logarithm of occupational fatality rates changes in a linear fashion over time. Other models could conceivably provide a more detailed description of the data, but the log linear model we used has been shown to be a reasonable fit to the data. ${ }^{7}$ Moreover, the phenomenon of primary interest in this study was the long term change in fatal injury rates over the entire study period, rather than changes on a shorter time scale. A log linear model provides a simple, readily interpretable description of this change.

The long term decline in the overall rate of fatal occupational injury is encouraging. At the same time, the disparities in trends of fatal injury rates across causes of death, regions, and demographic groups serve to draw attention to possible opportunities to reduce the risks workers face. Increasing injury rates deserve particular attention from policy makers, as well as from researchers.

\section{ACKNOWLEDGEMENT}

This research was partially supported by grant number R01-OH03910 to Dr Loomis from the National Institute for Occupational Safety and Health. 


\section{Authors' affiliations}

D Loomis, Department of Epidemiology, School of Public Health, University of North Carolina, Chapel Hill, North Carolina J F Bena, National Institute for Occupational Safety and Health, Cincinnati, Ohio

A J Bailer, National Institute for Occupational Safety and Health, Cincinnati, Ohio and Department of Mathematics and Statistics, Miami University, Oxford, Ohio

\section{REFERENCES}

1 Marsh SM, Layne LA. Fatal injuries to civilian workers in the United States, 1980-1995. Cincinnati, OH: 1993 (DHHS (NIOSH) Publication No 2001-129S)

2 Bailer AJ, Stayner LT, Stout NA, et al. Trends in rates of occupational fatal injuries in the United States (1983-92). Occup Environ Med 1998;55:485-9.

3 Stout NA, Jenkins EL, Pizatella TJ. Occupational injury mortality rates: changes from 1980 to 1989. Am J Public Health 1996;86:73-7.

4 Richardson DB, Loomis DP. Trends in fatal occupational injuries and industrial restructuring in North Carolina in the 1980s. Am J Public Health 1997;87:1041-3.

5 National Institute for Occupational Safety and Health, CDC, USDHHS. Fatal injuries to workers in the United States, 1980-1989: a decade of surveillance. Cincinnati, $\mathrm{OH}: 1993$ (NIOSH Publications Dissemination, Cincinnati, OH) (DHHS (NIOSH) Publication No 93-108S).

6 Loomis D, Richardson D, Wolf $S$, et al. Fatal occupational injuries in a southern state. Am J Epidemiol 1997;145:1089-99.
7 US Census Bureau, Department of Commerce. Census Regions and Divisions of the United States. US Census Bureau, geographic area reference manual (http://www.census.gov/ftp/pub/geo/www/ GARM/). Accessed 23 September 2002

8 Frome EL, Checkoway H. Use of Poission regression models in estimating incidence rates and ratios. Am J Epidemiol 1985;121:309-23

9 Bailer AJ, Reed LD, Stayner LT. Modeling fatal injury rates using Poisson regression: a case study of workers in agriculture, forestry, and fishing. $J$ Safety Res 1997; 28:177-86.

10 National Center for Injury Prevention and Control. Web-based injury statistics query and reporting system (http://www.cdc.gov/ncipc/ wisqars/). Accessed 16 May 2002

11 Falk WW, Lyson TA. High tech, low tech, no tech: recent industrial and occupational change in the south. Albany, NY: State University of New York Press, 1988.

12 Luebke P. Tarheel politics: myths and realities. Chapel Hill, NC: University of North Carolina Press, 1990.

13 Stout N, Bell C. Effectiveness of source documents for identifying fatal occupational injuries: a synthesis of studies. Am J Public Health 1991;81:725-8.

14 Gute DM, Fulton JP. Agreement of occupation and industry data on Rhode Island death certificates with two alternative sources of information. Public Health Rep 1985;100:65-72.

15 Russell J, Conroy C. Representativeness of deaths identified through the injury-at-work item on the death certificate: implications for surveillance. Am J Public Health 1991;81:1613-18.

16 Schade WJ, Swanson GM. Comparison of death certificate occupation and industry data with lifetime occupational histories obtained by interview: variations in the accuracy of death certificate entries. Am J Ind Med 1988;14:121-36.

\section{LACUNAE}

\section{UN child injury conference addresses one million preventable deaths}

O)

ne million children die of preventable injuries every year in the developing world, eclipsing death from infectious diseases, the United Nations Children's Fund (UNICEF) said ahead of a conference in Bangkok in October on the issue. Public health experts and academics specialising in the field of child injury attended the three day meeting sponsored by UNICEF and the US Centers for Disease Control. "Injury is a major cause of child death and disability today, but this is a phenomenon that can be prevented", said Pete Peterson, formerly the first US ambassador to Vietnam. Peterson, founder of The Alliance for Safe Children (TASC) which sprang from a campaign that began in Vietnam, said there was a lack of data, prevention programs, or research on injury in most developing countries. TASC aimed to serve as "a global catalyst to address and promulgate the issue of injury as the major killer of children and its detrimental impact on the public health systems of developing countries", he said. UNICEF said in a statement that of every 100000 children born in developing countries, 1000 will die from injuries before the age of 15. "There is growing evidence that preventable injuries-not infectious diseases-are the biggest killer of children in the developing world today", it said. The organisation said the conference aimed to develop a regional institutional alliance for child injury prevention, and eventually create a base of scientific evidence to promote prevention programs (contributed by Ian Scott). 